\title{
Innovore \\ Revista de ciencia y tecnologio \\ Consideraciones a propósito del interdicto de recobrar por despojo judicial: El caso en que el predio lanzado pertenece a otra persona
}

\author{
Jorge Isaac Torres Manrique ${ }^{1}$ \\ Investigador externo, Lima, Perú. \\ (Recibido: Mayo, 2015 y Aceptado: Julio, 2015)
}

\begin{abstract}
Resumen:
En la presente entrega, el autor aborda un tema relacionado a la efectivizacíón de la restitución judicial del derecho de posesión, a través del interdicto de recobrar, con la particularidad, que es interpuesto, en razón a que el predio lanzado es correspondiente a otra persona.
\end{abstract}

Palabras Claves: Interdicto, Interdicto de recobrar, Lanzamiento, Despojo judicial. .

\begin{abstract}
:
In this paper, the author addresses a topic related to the effectuation of court-ordered ownership restitution, through the injunction to repossess, with the peculiarity that it is filed because the said premise corresponds to another person.
\end{abstract}

Keywords: Injunction, Injunction to repossess, Launch, Judicial dispossession.

\section{Introducción.}

Como primer punto, he considerado abordar la importancia y trascendencia que abraza a la casación civil, en tanto se yergue como el medio impugnatorio de mayor renombre de nuestro ordenamiento jurídico peruano, pues tiene el mérito de constituirse en el recurso en el que más se pone a prueba los conocimientos jurídicos; tanto del juzgador, como del abogado patrocinante del recurrente.

Entonces, se tiene que la casación debiera ser únicamente de naturaleza extraordinaria, en la medida que; no es cualquier juez el llamado a conocerla y resolverla si no, solo los magistrados supremos. De igual forma porque solo un abogado bien entrenado en las sutilezas y características especiales de este recurso, estaría en condiciones apropiadas para presentarla y sustentarla. ${ }^{2}$

Por otro lado, no menos importante merece el tema del análisis y crítica a las resoluciones jurisdiccionales, como la que importa la naturaleza de la presente entrega. En razón, a que ello significa que existe efectivamente escenarios de reflexión y retroalimentación, así también, que el derecho esquiva o aleja los temidos periodos estancos y en su caso, de retroceso.

Y es que, tal y como lo señala el Art. 139, inc. 20 de la Constitución de 1993, repitiendo así el aserto consagrado en la anterior Carta de 1979, en el sentido que toda persona tiene

\footnotetext{
${ }^{1}$ Investigador Externo Adscrito al Instituto Vasco de Derecho Procesal (País Vasco). Colaborador Externo del Bufete Jurídico Internacional, Jordan \& Luciano Abogados (España). Experto en Derecho Empresarial y Administrativo, en Avalón, la Red de Expertos de España, Portugal y Latinoamérica (España). Abogado por la Universidad Católica de Santa María (Arequipa -Perú). Egresado de los Doctorados en Derecho y Administración, y de las Maestrías en Derecho Empresarial y Derecho Penal, por la Universidad Nacional Federico Villarreal (Lima -Perú). Email: kimblellmen@outlook.com.

2 Véase: TORRES CARRASCO, Manuel Alberto. El nuevo recurso de casación civil. Recientes modificaciones y repaso jurisprudencial. Grupo Editorial Gaceta Jurídica. Lima, 2010, p. 05.
} 
derecho de formular análisis y críticas de las resoluciones y sentencias judiciales (con las limitaciones de ley), lo que debe entenderse no limitado al Poder Judicial, sino también el Tribunal Constitucional. ${ }^{3}$

Sin embargo, sin perjuicio de lo referido, estimo que no solamente en materia de formulación de análisis y críticas de las resoluciones y sentencias judiciales, ello constituye además una obligación y auto compromiso. Así, parafraseando al jurista Marcial Rubio Correa ${ }^{4}$, dejo expresa constancia, que lo esbozado y concluido en el presente trabajo; contiene únicamente un carácter conclusivo, más para nada, definitivo. En ese orden de ideas, abogo porque de modo permanente debemos bregar por encontrarnos siempre situados y comprometidos en la vereda de la admiración, cuestionamiento y proposicionamiento; mas nunca en el de la mera repetición e impertérrita contemplación y peor aún, en el de la muy penosa como patética indiferencia.

En ese sentido, el Tribunal Constitucional peruano (Exp. No 04-2006-AI/TC, f.j. 18) ha señalado que el derecho a la crítica de las resoluciones judiciales: "es el derecho de toda persona de examinar y emitir juicios públicamente respecto de las decisiones que adoptan los jueces en todas las especialidades”. Así también, que entre los límites al derecho a la crítica de las resoluciones judiciales, destaca, entre otros, que ésta no deba servir para orientar o inducir a una determinada actuación del juez, pues, éste solo se encuentra vinculado por la Constitución y la ley que sea conforme a ésta. ${ }^{5}$

Precisamente, el presente trabajo se enfoca en dicho derrotero, esto es, desarrollar lo concerniente a los alcances de la Resolución expedida por la Sala Civil Transitoria de la Corte Suprema de Justicia de la República del Perú (Cas. N 986-2012 Ayacucho), la misma que versa sobre el interdicto de recobrar por despojo judicial, en el supuesto en que el predio lanzado pertenece a otra persona.

\section{Acerca de los orígenes de los interdictos.}

Entre los interdictos que conoció el derecho romano, se encuentran los de vi (despojo violento sin armas) y los de vi armata (despojo violento con armas), los que eran recuperatorios y se dirigían a proteger al poseedor que había sido víctima de despojo violento, ordenando que se le restituyera la posesión. El primero suponía un despojo violento, pero, sin hacer uso de armas, y se exigía que el poseedor demandante poseyera con anterioridad al despojo nec vi nec clam nec precario (ni la fuerza ni un secreto ni una precaria). El interdicto de vi armata, suponía según BIONDI una violencia grave o vis astros (ilimitada), llevada a cabo con el uso de armas y se concedía sin límite alguno de tiempo, a cualquier tipo de poseedor, aunque este poseyera aut vi aut clam (por la fuerza o por el fraude). ${ }^{6}$

Por su parte, en el derecho de Inglaterra o anglosajón, es de verse que los interdictos o injunctions, fueron creados por la equidad, y son órdenes de los tribunales que mandan que se haga algo (interdicto ordenador), o que prohíbe algo (interdicto prohibitivo). Como

\footnotetext{
${ }^{3}$ Vide GARCÍA BELAÚNDE, Domingo. Diccionario de jurisprudencia constitucional. Definiciones y conceptos extraídos de las resoluciones y sentencias del tribunal constitucional. Editora Jurídica Grijley, Lima, 2009, p. VII).

${ }^{4}$ Vide VALDIVIA CANO, Juan Carlos. La caja de herramientas (introducción a la investigación jurídica), Impresiones Zenith. Arequipa. 1998, p. 08.

${ }^{5}$ Cfr. GARCÍA BELAÚNDE. Ob. cit, pp. 726-727.

${ }^{6}$ Cfr. DIEZ- PICAZO, Luis. Fundamentos del derecho civil patrimonial. Editorial Tecnos S.A. Madrid. Volúmen II, 1983, p. 540.
} 
alternativa para reclamar una indemnización por daños, el demandante puede pedir un interdicto para evitar la comisión o la continuidad de un acto ilícito civil. Al ser remedios de la equidad, los interdictos únicamente eran concedidos por el Tribunal de la Cancillería. Eran discrecionales, ergo, el tribunal no estaba obligado a concederlos y normalmente no los concedía cuando una indemnización por daños servía de adecuada compensación. ${ }^{7}$

Luego, tenemos que el primer vocablo proviene del latín interdictum (entredicho) y que constituye un procedimiento en materia civil encaminada a obtener del juez una resolución rápida, que se dicta sin perjuicio de mejor derecho, a efectos de evitar un peligro o de reconocer un derecho posesorio. Seguidamente, en lo que respecta al interdicto de recobrar o recuperar, es utilizado cuando el poseedor ha sido despojado de ella por un tercero. ${ }^{8}$

\section{En lo tocante al interdicto de recobrar.}

Respecto del interdicto de recobrar, tenemos que el Art. 603, del Código Procesal Civil peruano, dispone: "Procede cuando el poseedor es despojado de su posesión, siempre que no haya mediado proceso previo. Sin embargo, si se prueba que el despojo ocurrió en ejercicio del derecho contenido en el artículo 920 del Código Civil, la demanda será declarada improcedente".

Por su parte, es de verse, que el Art. 921.-, del Código Civil peruano, establece: “Todo poseedor de muebles inscritos y de inmuebles puede utilizar las acciones posesorias y los interdictos. Si su posesión es de más de un año puede rechazar los interdictos que se promuevan contra él”.

Así también, el interdicto de recobrar es entendido como un juicio posesorio sumarísimo, que tiene por objeto reintegrar y reponer inmediatamente en la posesión o tenencia de un bien, al que gozaba de ella, de la cual otro le ha despojado violenta o clandestinamente, por su propia autoridad. Su fundamento reside en el principio de que nadie puede hacerse justicia por sí mismo, si no, recurriendo a las autoridades judiciales instituídas para administrarla a cada uno. ${ }^{9}$

Empero, además, el interdicto de recobrar viene a ser un remedio rápido y abreviadísimo para las situaciones de hecho, resultando ajenas a sus estrechos límites la discusión y resolución de los derechos u obligaciones basados en relaciones contractuales -v.gr.: un boleto de compraventa- siendo su objeto, proteger el hecho de la mera tenencia de las cosas o en su caso, la posesión actual, habiendo sido instituído para evitar que nadie zanje sus conflictos por propia mano. ${ }^{10}$

\footnotetext{
${ }^{7}$ Cfr. JAMES, Philip. Introducción al derecho inglés. Editorial Temis S.A. Santa Fe de Bogotá. 1996, p. 340.

${ }^{8}$ Veni OSSORIO. Manuel. Diccionario de ciencias jurídicas, políticas y sociales. Editorial Heliasta S.R.L. Buenos Aires. 2001, p. 528.

${ }^{9}$ Vide ARAGÓN L., Luis Ángel. Diccionario jurídico de derecho procesal civil. IDEA Editores. Lima, 1995, p. 153.

${ }^{10}$ Véase: GOZAÍNI, Oswaldo Alfredo. Elementos de derecho procesal civil. EDIAR S. A. Editora, Comercial, Industrial y Financiera. Buenos Aires, 2005, p. 635.
} 


\section{Referente al derecho a la posesión.}

$\mathrm{Al}$ respecto, es de verse que el Art. 896.-, del Código Civil peruano, juridiza que: "La posesión es el ejercicio de hecho de uno o más poderes inherentes a la propiedad”.

En ese sentido, la posesión no sería más que la emanación que se tiene sobre una cosa. Sin embargo, la posesión adquiere una relevancia jurídica propia, precisamente porque el ordenamiento jurídico contempla aquel señorío o poder de hecho sobre la cosa desvinculado del derecho. Así, se fija en la situación jurídica (por los defectos que le atribuye), en la que aparece una persona en una relación fáctica con la cosa. Ergo, la posesión sería la cara visible de una moneda, cuya otra cara estaría representada por el derecho que emana aquella posesión. Entonces, el ordenamiento jurídico, al contemplar la posesión, centra su atención en la cara visible, sin averiguar si efectivamente la moneda tiene efectivamente la otra cara (el derecho), o se halla en blanco (se posee sin derecho alguno de donde provenga la posesión). ${ }^{11}$

Entonces, se trata pues, del reconocimiento del derecho posesorio y como tal es derecho material, pero, con efectos procesales. Así, se tiene que, acreditado el derecho, la demanda que va contra el mismo, será declarada improcedente. ${ }^{12}$

\section{Sobre el lanzamiento judicial.}

Mediante el lanzamiento, el juez con apoyo de la autoridad policial, hace efectiva la desocupación de un determinado inmueble cuando, durante la tramitación de un proceso, se haya determinado que un sujeto que carece de un título válido que le permita ostentar la posesión de manera legítima, tiene el bien bajo su esfera de control, con directo menoscabo del propietario o poseedor legítimo. Dicho procedimiento es un acto típico de los procesos de desalojo. Es así, que la doctrina señala que las sentencias de desalojo se ejecuta a través del lanzamiento que es: "el acto mediante el cual, con intervención del oficial y el eventual auxilio de la fuerza pública, se hace efectiva la desocupación del inmueble por el inquilino y demás ocupantes”. Sin embargo, el proceso de desalojo no es el único supuesto en el cual se emplea dicho procedimiento. Así por ejemplo, el Código Procesal Civil peruano, contempla dos situaciones adicionales donde se emplea el desalojo, tales como: i) en el proceso de reivindicación y ii) en el remate judicial (Vide: Art. 739 del CPC). ${ }^{13}$

Así también, tenemos que constituye una diligencia propia del periodo de ejecución de sentencia, en los juicios de desalojo o desahucio. Para proceder esta diligencia, es necesario que la sentencia dictada por el juez competente sea firme y que medie instancia de parte. El juez deberá, al ordenar el lanzamiento, proceder de acuerdo con la ley, esto es, otorgando los plazos que esta establece. ${ }^{14}$

\footnotetext{
${ }^{11}$ Vide DIEZ- PICAZO, Luis y GULLÓN, Antonio. Sistema de derecho civil. Editorial Tecnos S.A. Madrid. Tomo III, 1981, p. 109.

${ }^{12}$ Cfr. SAGÁSTEGUI URTEAGA, Pedro. Exégesis y sistemática del código procesal civil. Volúmen II. Editora Jurídica Grijley, Lima, 2003, p. 267.

${ }^{13}$ ACOSTA OLIVO, Carlos. En: VV. AA. Diccionario procesal civil. Grupo Editorial Gaceta Jurídica. Lima, 2013, p. 193.

${ }^{14}$ Ver CABANELLAS, Guillermo. Diccionario enciclopédico de derecho usual. Editorial Heliasta. 23 ${ }^{\mathrm{a}}$ edición. Tomo V. Buenos Aires. 1994, p. 87.
} 


\section{Acerca del principio procesal del debido proceso.}

El debido proceso, estatuído genéricamente como garantía, salió a la luz del mundo del derecho, en primer lugar: en el common law inglés, en la Carta Magna de Inglaterra del 15/06/1215 (Concesión Real o cédula del rey Juan Sin Tierra inglés, por la cual se comprometió con los nobles ingleses, a respetar sus fueros e inmunidades y a no disponer su muerte, prisión y confiscación de sus bienes, mientras dichos nobles no fuesen juzgados por sus iguales); y en segundo lugar: aparece expresamente en la Quinta Enmienda de la Constitución Política de EE. UU. de 1787- Carta de Derechos- (la misma que prohíbe los juicios repetidos por el mismo delito conocido como double jeopardy y los delitos sin el debido proceso legal, así como también, el que una persona acusada no esté obligada a atestiguar contra si misma).

Por otro lado, el debido proceso es un "derecho continente” pues, contiene, agrupa o engloba otros derechos, los cuales se encuentran contemplados en una Convención y Convenio Internacional de DD. HH., así tenemos respectivamente: fue regulado como: i) garantía judicial ha sido regulado por el art. 8 de la Convención Americana sobre Derechos Humanos suscrita en la Conferencia Especializada Interamericana sobre Derechos Humanos (San José, Costa Rica 7-22/11/1969), denominada también Convención Americana sobre Derechos Humanos (Pacto de San José) ${ }^{15}$; y además, ii) el debido proceso, a través del derecho a un proceso equitativo, también fue contemplado por el art. 6 del Convenio Europeo para la Protección de los Derechos Humanos y de las Libertades Fundamentales revisado de conformidad con el Protocolo $\mathrm{N}^{\circ} 11$, completado por los Protocolos No 1 y 6 (septiembre 2003). ${ }^{16}$

\footnotetext{
${ }^{15}$ Artículo 8. Garantías Judiciales.- 1. Toda persona tiene derecho a ser oída, con las debidas garantías y dentro de un plazo razonable, por un juez o tribunal competente, independiente e imparcial, establecido con anterioridad por la ley, en la sustanciación de cualquier acusación penal formulada contra ella, o para la determinación de sus derechos y obligaciones de orden civil, laboral, fiscal o de cualquier otro carácter. 2. Toda persona inculpada de delito tiene derecho a que se presuma su inocencia mientras no se establezca legalmente su culpabilidad. Durante el proceso, toda persona tiene derecho, en plena igualdad, a las siguientes garantías mínimas: a) derecho del inculpado de ser asistido gratuitamente por el traductor o intérprete, si no comprende o no habla el idioma del juzgado o tribunal; b) comunicación previa y detallada al inculpado de la acusación formulada; c) concesión al inculpado del tiempo y de los medios adecuados para la preparación de su defensa; d) derecho del inculpado de defenderse personalmente o de ser asistido por un defensor de su elección y de comunicarse libre y privadamente con su defensor; e) derecho irrenunciable de ser asistido por un defensor proporcionado por el Estado, remunerado o no según la legislación interna, si el inculpado no se defendiere por sí mismo ni nombrare defensor dentro del plazo establecido por la ley; f) derecho de la defensa de interrogar a los testigos presentes en el tribunal y de obtener la comparecencia, como testigos o peritos, de otras personas que puedan arrojar luz sobre los hechos; g) derecho a no ser obligado a declarar contra sí mismo ni a declararse culpable, y h) derecho de recurrir del fallo ante juez o tribunal superior. 3. La confesión del inculpado solamente es válida si es hecha sin coacción de ninguna naturaleza. 4. El inculpado absuelto por una sentencia firme no podrá ser sometido a nuevo juicio por los mismos hechos. 5 . El proceso penal debe ser público, salvo en lo que sea necesario para preservar los intereses de la justicia. LANDA ARROYO, C. (2005). Compilador. Jurisprudencia de la corte interamericana de derechos humanos. Palestra Editores. Lima, pp. 1301- 1302.

${ }^{16}$ Artículo 6. Derecho a un proceso equitativo.- 1 . Toda persona tiene derecho a que su causa sea oída equitativa, públicamente y dentro de un plazo razonable, por un tribunal independiente e imparcial, establecido por la ley, que decidirá los litigios sobre sus derechos y obligaciones de carácter civil o sobre el fundamento de cualquier acusación en materia penal dirigida contra ella. La sentencia debe ser pronunciada públicamente, pero el acceso a la sala de audiencia puede ser prohibido a la prensa y al público durante la totalidad o parte del proceso en interés de la moralidad, del orden público o de la seguridad nacional en una sociedad democrática, cuando los intereses de los menores o la protección de la vida privada de las partes en el proceso así lo exijan o en la medida en que será considerado estrictamente necesario por
} 
El debido proceso, además, es reconocido en el inc. 3 del art. 139 de la Constitución Política peruana, que señala: "son principios y derechos de la función jurisdiccional, la observancia del debido proceso y la tutela jurisdiccional”.

Tenemos que, ostentan la titularidad del derecho al debido proceso y la tutela jurisdiccional no solamente las personas naturales, también las personas jurídicas de derecho privado (Exp. No 0905-2001-AA/TC y N 4972-2006- PA/TC), así también lo propio, las personas jurídicas de derecho público (en efecto, el Tribunal Constitucional peruano -Exp. Nº1407-2007-PA/TC, 14/08/08) -ha sostenido que, estas últimas (es decir, las personas jurídicas de derecho público) son poseedoras de dicha titularidad, incluso en la etapa prejurisdiccional a cargo del Ministerio Público.

Para DEVIS ECHANDÍA, citado por SAGÁSTEGUI URTEAGA, ${ }^{17}$ el concepto del debido proceso puede estar integrado por las siguientes condiciones: i) dotar al juez para que procure hacer efectiva la igualdad de las partes en el proceso, protegiendo al débil que siempre es el más pobre, ii) inmediación del Juez sobre el material probatorio y sobre los sujetos del proceso, iii) aceleración del proceso, en cuanto sea posible dentro del sistema parcial de la escritura, iv) carácter dispositivo del proceso en cuanto a su iniciación y a la libertad para concluirlo por transacción o desistimiento, si las partes son incapaces mediante licencia previa, v) carácter inquisitivo en materia de pruebas, vi) valoración de las pruebas de acuerdo con las reglas de la sana crítica y mediante una adecuada motivación, vii) una combinación del impulso del juez de oficio y del secretario, una vez iniciado el proceso con la perención por incumplimiento de la carga de las partes de promover su trámite si aquellos no cumplen oficiosamente, viii) responsabilidad civil de los jueces, partes y apoderados por sus acciones en el proceso, ix) amplias facultades al Juez para prevenir y sancionar el fraude procesal con el proceso y en el proceso y todo acto de deslealtad o mala fe de las partes, los apoderados y los terceros, x) simplificación de los procesos especiales innecesarios, xi) el principio de las dos instancias como regla general, y xii) gratuidad de la justicia civil.

Por nuestra parte, sostengo que el debido proceso es el derecho de los particulares a un proceso judicial sin postergaciones, retrasos, alteraciones o deformaciones, durante el camino, devenir o desenvolvimiento lógico procesal del mismo; que desvirtúen su finalidad que es la justicia. Consecuentemente, queda claro que, prima facie, el derecho que tienen los particulares a un juicio justamente debido, el cual presente las suficientes motivaciones, fundamentos o argumentos jurídicos, que justifiquen lo acontecido en las diversas etapas de dicho proceso.

el tribunal, cuando en circunstancias especiales la publicidad pudiera ser perjudicial para los intereses de la justicia. 2. Toda persona acusada de una infracción se presume inocente hasta que su culpabilidad haya sido legalmente declarada. 3. Todo acusado tiene, como mínimo, los siguientes derechos: a) a ser informado, en el más breve plazo, en una lengua que comprenda y detalladamente, de la naturaleza y de la causa de la acusación formulada contra él; b) a disponer del tiempo y de las facilidades necesarias para la preparación de su defensa; c) a defenderse por sí mismo o a ser asistido por un defensor de su elección y, si no tiene medios para pagarlo, poder ser asistido gratuitamente por un abogado de oficio, cuando los intereses de la justicia lo exijan; d) a interrogar o hacer interrogar a los testigos que declaren contra él y a obtener la convocación e interrogación de los testigos que declaren en su favor en las mismas condiciones que los testigos que lo hagan en su contra; e) a ser asistido gratuitamente de un intérprete, si no comprende o no habla la lengua empleada en la audiencia. DÍAZ REVORIO, F. J. (2004). Compilador. Jurisprudencia del tribunal europeo de derechos humanos. Palestra editores. Lima, pp. 947- 948.

${ }^{17}$ Cfr. SAGÁSTEGUI URTEAGA. Ob. cit. Volúmen I, pp. 08-09. 
Por otro lado, es preciso tener en cuenta que el debido proceso contempla tres modalidades: i) “jurisdiccional”, que garantiza un proceso debido a nivel judicial, arbitral, militar y comunal, ii) "administrativo”, que garantiza lo propio en sede de la administración pública, y iii) “corporativo particular”, que garantiza también un debido proceso entre particulares.

Asimismo, el debido proceso posee dos dimensiones: i) “adjetiva o formal”, como garante de un desenvolvimiento o desarrollo procesal debido, y ii) "sustantiva o material”, como garante de una decisión judicial basada o enmarcada tanto en la razonabilidad y proporcionalidad, es decir, garantiza una sentencia justa.

Con respecto a los elementos del debido proceso, TICONA POSTIGO, citando a HOYOS, refiere que los mismos serían: i) La regulación legal de los procesos y su desarrollo sin dilaciones, ii) El derecho a ser oído, iii) Tribunal competente, predeterminado, independiente e imparcial, iv) Contradicción y bilateralidad: oportunidad de tomar posición y pronunciarse sobre las pretensiones del actor y las manifestaciones de la parte contraria, v) El derecho de aportar pruebas lícitas relacionadas con el objeto del proceso y de contradecir las aportadas por la otra parte o por el juez, vi) La facultad de hacer uso de los medios impugnatorios previstos en la ley contra resoluciones judiciales motivadas, y vii) Respeto a la cosa juzgada. ${ }^{18}$

\section{En lo que respecta a la motivación de las resoluciones judiciales.}

En primer lugar, en lo relacionado a las decisiones basadas en la argumentación, amerita traer a colación, el surgimiento y contenido de la teoría de la argumentación.

Así, la existencia de un amplio campo para el intérprete y el aplicador del derecho, constituyó a éste en protagonista de la historia, pero, ya no es sencillo sostener que su tarea se limita a identificar un supuesto de hecho y subsumirlo en una norma. Por el contrario, debe argumentar frente al caso, utilizando la norma como un instrumento más. Entre las principales características de esta tesis, podemos citar: i) El derecho es una ciencia de problemas y no meramente especulativa, ii) La tarea del juez es el ejercicio de la prudencia y no la especulación, iii) La prudencia se basa en el ejercicio argumentativo, iv) Argumentar es convencer a un auditorio imaginario, esto es, a quienes va destinada la decisión, y v) La argumentación se basa en la experiencia previa acumulada (tópicos), o en la capacidad del argumento para persuadir a un auditorio universal, utilizado como modelo. ${ }^{19}$

Entonces, resulta pertinente que el derecho a que las resoluciones judiciales sean razonadas, garantiza que la decisión adoptada no sea fruto de la arbitrariedad, del voluntarismo judicial o acaso consecuencia de un proceso deductivo irracional, absurdo o manifiestamente irrazonable. Ciertamente, no está dentro de su ámbito protegido el acierto o no que esta pudiera tener, o acaso, que no constituya una infracción de la ley. ${ }^{20}$

\footnotetext{
${ }^{18}$ Véase: TICONA POSTIGO, Víctor. El derecho al debido proceso en el derecho civil. Editora Jurídica Grijley, Lima, p. 122.

${ }^{19}$ Cfr. LORENZETTI, Ricardo Luis. Razonamiento judicial. Fundamentos de derecho privado. Editora Jurídica Grijley E.I.R.L. Lima, 2006, p. 219.

20 Sentencia del Tribunal Constitucional peruano, Exp.458-2001- HC. En línea: Recuperada en fecha 18/04/15 de: http://www.tc.gob.pe/jurisprudencia/2002/00458-2001-HC.html. Lima. 2002.
} 
Además, uno de los contenidos del debido proceso, es el derecho a obtener de los órganos judiciales, una respuesta motivada, razonada y congruente con las pretensiones oportunamente deducidas por las partes, en cualquier clase de proceso. La exigencia que las decisiones judiciales sean motivadas en proporción a los términos del Inc. 5), del Art. $139^{\circ}$, de la Norma Fundamental, garantiza que los jueces, cualquiera sea la instancia a la que pertenezcan, expresen el proceso mental que los ha llevado a decidir una controversia, asegurando que el ejercicio de administrar justicia se haga con sujeción a la Constitución y a la ley; pero también, con la finalidad de facilitar un adecuado ejercicio del derecho de defensa de los justiciables (Exp. 1230-2002-HC/TC). ${ }^{21}$

La motivación de las resoluciones judiciales, constituye el conjunto de razonamientos de hecho y derecho realizados por el juzgador, en los cuales apoya su decisión. Así por ejemplo, tal vez la causa por la que un juez declara fundada una demanda sobre daños y perjuicios, sea la compasión que le produce la precaria o lastimosa situación del demandante, mas ello no sirve como justificación jurídica. En este caso, solo se tratará de una motivación judicial en apariencia. ${ }^{22}$

\section{En atinencia al principio procesal de congruencia.}

En primer término, es de considerar que este principio se constituye quizás en el de mayor relevancia, ya que se constituye en un verdadero reto (trascendentalmente geológico, digamos) para el juzgador al resolver (vía sentencia) conforme lo que las partes solicitaron (es decir, ni menos, ni más de lo pedido, peor aún distinto). De tal modo, los demás principios procesales civiles, no tendrían razón de ser en el supuesto que el juez no expida su fallo en abierta violación del principio de congruencia. Además de lo señalado, tenemos que agregar que las mismas estarán lógicamente expectantes a lo resuelto. Consecuentemente, el compromiso del juzgador con dicho principio abarca una esfera saludablemente más amplia y compleja (es decir, con el proceso y con las partes).

En el mismo sentido se expresa RIBÓ DURAND, ${ }^{23}$ quien refiere: “es la cualidad técnica más importante que debe tener toda sentencia, consiste en la vinculación entre la pretensión procesal y lo decidido en la sentencia. Por ello se dice que hay sentencia congruente con la demanda y con las demás pretensiones oportunamente deducidas en el litigio, cuando la sentencia hace las declaraciones que aquellas exijan, condenando o absolviendo al demandado y decidiendo todos los puntos litigiosos que hayan sido objeto de debate. La sentencia no ha de contener más de lo pedido por los litigantes; de lo contrario, incurriría en incongruencia positiva. La incongruencia negativa surge cuando la sentencia omite decidir sobre alguna de las pretensiones procesales. Si la sentencia decide sobre algo distinto de lo pedido por los litigantes, se produce la incongruencia mixta. La sentencia incongruente puede ser objeto de impugnación por la vía del recurso oportuno”.

\footnotetext{
${ }^{21}$ Véase: GARCÍA BELAÚNDE. Cit, p. 483

${ }^{22}$ CASTILLO ALVA, José Luis. LUJÁN TÚPEZ, Manuel y ZAVALETA RODRIGUEZ, Roger. Razonamiento judicial. Interpretación, argumentación y motivación de las resoluciones judiciales. Editorial Gaceta Jurídica S.A. Lima, 2004, pp. 335- 336.

${ }^{23}$ Véase: RIBÓ DURAND, Luis. Diccionario de derecho. Bosh Casa Editorial. S. A. Barcelona. 1987, p. 137.
} 
Así también lo señala MONROY GÁLVEZ 24: “el principio de congruencia judicial exige al juez que no omita, altere o exceda las pretensiones contenidas en el proceso que resuelva”.

Seguidamente, es importante tomar en cuenta que la congruencia de dicho principio se encuentra relacionada no solo con el sentido, sino también con el alcance de las mismas. Así lo afirma MONROY CABRA, ${ }^{25}$ citando a DEVIS ECHANDÍA, al señalar que "se entiende por congruencia o consonancia el principio normativo que delimita el contenido de las resoluciones judiciales que deben proferirse, de acuerdo con el sentido y alcance de las peticiones formuladas por las partes (en lo civil, laboral y contencioso administrativo) o de los cargos o imputaciones penales formulados contra el sindicato o imputado, sea de oficio o por instancia del ministerio público o del denunciante o querellante (en el proceso penal), para el efecto que exista identidad jurídica entre lo resuelto y las pretensiones o imputaciones y excepciones o defensas oportunamente aducidas, a menos que la ley otorgue facultades especiales para separarse de ellas”.

Líneas abajo, el primero de los autores citados, ${ }^{26}$ Acota: “en relación con las pretensiones, la incongruencia tiene tres aspectos: a) cuando se otorga más de lo pedido (plus petita o ultra petita); b) cuando se otorga algo distinto de lo pedido (extra petita); y c) cuando se deja de resolver sobre algo pedido (citra petita)”.

Empero, si con ello no bastase, la importancia del principio procesal de congruencia también radica en su naturaleza constitucional connatural al derecho de defensa. En respuesta a lo reseñado, DEVIS ECHANDÍA, ${ }^{27}$ sostiene que "tiene extraordinaria importancia este principio, pues se liga íntimamente con el derecho constitucional de defensa, ya que este exige que el ajusticiado en cualquier clase de proceso conozca las pretensiones o las imputaciones que contra él o frente a él se han formulado, por lo que la violación de la congruencia implica la de aquel derecho; la actividad probatoria, las excepciones o simples defensas y las alegaciones, se orientan lógicamente por las pretensiones, imputaciones, excepciones y defensas formuladas en el proceso. También se relaciona con la cosa juzgada, para determinar el verdadero sentido de ésta”.

De similar opinión (es decir, respecto de la relación congruencia y defensa) son CASTILLO QUISPE y SÁNCHEZ BRAVO, ${ }^{28}$ quienes citando a ALDO BACRE, señalan respecto del principio de congruencia procesal: "El juez debe fallar de conformidad con las pretensiones deducidas en el juicio, es decir que debe haber conformidad entre la sentencia y lo pedido por las partes (sea en demanda, reconvención y contestación de ambas, inclusive), en cuanto a las personas, el objeto y la causa, porque el oficio no puede apartarse de los términos en que ha quedado planteada la litis en la relación procesal. Con la contestación a la demanda se integra la relación procesal produciendo dos efectos fundamentales: quedan determinados los sujetos de la relación

\footnotetext{
${ }^{24}$ Vici, en ese sentido MONROY GÁLVEZ, Juan. Introducción al proceso civil. Editoriales Temis S. A. y De Belaunde \& Monroy. Santa Fe de Bogotá. 1996, p. 91.

${ }^{25}$ Vide MONROY CABRA, Marco Gerardo. Principios del derecho procesal civil. Editorial Temis S.A. Bogotá, 1973, pp. 55 -56.

${ }^{26}$ Vici Ibid.

${ }^{27}$ Cfr. DEVIS ECHANDÍA, Hernando. Teoría general del proceso aplicable a toda clase de procesos. Tomo I. Editorial Universidad. Buenos Aires. 1984, pp. 49- 50.

${ }^{28}$ Veni CASTILLO QUISPE, Máximo y SÁNCHEZ BRAVO, Edgard. Manual de derecho procesal civil. Jurista Editores. Lima. 2007, pp. 44- 45.
} 
(actor + demandado) y las cuestiones sometidas al cuestionamiento del juez. Por lo tanto, los términos en que se han planteado la pretensión y la oposición a la misma son los que han de determinar el contenido de la sentencia, conforme el principio de congruencia, sino se quiere afectar el derecho de defensa de las partes, decidiendo sobre cuestiones no traídas a la litis u omitiendo resolver sobre alguna de ellas”.

Finalmente, MORALES GODO, ${ }^{29}$ esboza un óptica adicional, acotando: “el principio de congruencia en consecuencial al principio dispositivo. A través de dicho principio el Juez está en la obligación de resolver todas las pretensiones planteadas por las partes en el proceso, y solo ellas, ya que no podrá resolver pretensiones que no han sido invocadas, ni discutidas en el proceso".

A propósito, es de verse que el principio procesal de congruencia, bajo análisis, se encuentra regulado en el segundo párrafo del Artículo VII del Título Preliminar del Código adjetivo peruano citado, al indicar que el juez no puede ir más allá del petitorio, ni fundar su decisión en hechos diversos de los que hayan sido alegados por las partes.

Sin embargo, es preciso dejar constancia que inexplicablemente, el presente principio ha merecido un limitado interés, respecto de otros que también inspiran el derecho adjetivo civil peruano, por parte de la doctrina (sobre todo si consideramos su gravitante importancia). En ese sentido, agrego que mayor fortuna tuvo la primera parte del referido artículo, la misma que trata acerca del principio: juez y derecho (iura novit curia). Lo anecdótico es que en ambos casos, dichos principios no figuran textualmente en nuestro código procesal, sino solo implícitamente. En tal sentido, el tema del interés no obedece a la naturaleza no expresa de ambos en dicho Código.

\section{A propósito del principio de valoración conjunta de la prueba.}

El Art. 197.-, del Código Procesal Civil peruano juridiza: “Todos los medios probatorios son valorados por el Juez en forma conjunta, utilizando su apreciación razonada. Sin embargo, en la resolución sólo serán expresadas las valoraciones esenciales y determinantes que sustentan su decisión”.

Pero, a propósito... ¿Qué significa valorar la prueba? Al respecto, resulta pertinente señalar que, el juez no tiene la obligación de ocuparse de todas las pruebas, si no; de señalar cual de ellas le significa más que otras. Por ello, lleva a cabo un orden de selección y calificación donde interactúan distintas contingencias que van a influenciar la posibilidad de análisis, pero, toda la prueba colectada en autos debe ser apreciada en su conjunto por el principio de unidad de la prueba, atento que en la generalidad de los casos se llega a la convicción por medio de una evaluación de la totalidad de los medios probatorios y de consideración aislada de ellos. ${ }^{30}$

Sin perjuicio de lo mencionado, la citada norma tiene que aplicarse e interpretarse en forma sistemática con el Art. 188, del mismo cuerpo de leyes, referido a la finalidad de los medios probatorios, es decir, a acreditar los hechos expuestos por las partes, producir certeza en el Juez respecto de los puntos controvertidos y fundamentar su decisión. Igualmente con el Art. 200, que establece que si no se prueban los hechos que sustentan la pretensión, la demanda será declarada infundada, debiendo aplicarse el mismo criterio

\footnotetext{
${ }^{29}$ Cfr. MORALES GODO, Juan. Instituciones de derecho procesal. Palestra Editores. Lima. 2005. p. 410.

${ }^{30}$ GOZAÍNI, Oswaldo Alfredo. Ob. cit., p. 317.
} 
en caso que exista reconvención. Por otro lado, la valoración de la prueba que el Juez debe hacer en forma conjunta al momento de resolver la causa, no debe confundirse con la calificación que el Juez también realiza sobre los medios probatorios en forma individual en etapas procesal distintas a la resolución de la causa, nos referimos a lo previsto en el Art.190 del Código Procesal Civil peruano, que señala que los medios probatorios deben referirse a los hechos y a la costumbre cuando ésta sustenta la pretensión, de lo contrario serán declarados improcedentes. Igualmente, en este artículo se mencionan otros supuestos de improcedencia de medios probatorios, como por ejemplo que tiendan a establecer hechos no controvertidos, imposibles o que sean notorios o de pública evidencia. Es obvio que el Juez debe evaluar la pertinencia, idoneidad y utilidad de los medios probatorios, lo cual no debe llevar al error de considerar esta labor como de valoración de estos últimos. ${ }^{31}$

\section{Síntesis de la resolución casatoria sub exámine.}

La misma versa acerca de la Resolución expedida por la Sala Civil Transitoria de la Corte Suprema de Justicia de la República (Cas. N 986-2012 Ayacucho).

Respecto de los hechos, podemos señalar que Rina Paola Guzmán Pariona interpone demanda de Interdicto de Recobrar contra la empresa Negusa Corp. Sociedad Anónima, solicitando que se le restituya la posesión del inmueble ubicado en la Avenida Salvador Cavero número trescientos noventa y uno y trescientos noventa y cinco, Distrito El Nazareno, con ciento setenta y nueve metros cuadrados (179 m2) de área y, se ordene el pago de mil dólares americanos (US\$1,000.00) mensuales, por daños y perjuicios, a partir de la fecha de ministración de la posesión.

La referida resolución argumenta, que en el proceso de Ejecución de Garantías seguido por la empresa demandada contra su señora madre Roberta Pariona Vilcatoma, se remató y adjudicó el inmueble hipotecado ubicado en la tercera cuadra de la Avenida Salvador Cavero, sin embargo, el lanzamiento no se ejecutó en el predio hipotecado de propiedad de su madre, sino en el predio de propiedad de la recurrente, colindante con el de su madre, pero perfectamente diferenciable, ministrándose la posesión a favor de la empresa Negusa Corp. Sociedad Anónima, no obstante su presencia en la diligencia de lanzamiento y su oposición, negándose la Jueza a dejar constancia de que estaba procediendo la diligencia en predio ajeno.

A continuación, se tiene que por sentencia de primera instancia, el Juez del Segundo Juzgado Civil de Ayacucho, declara fundada la demanda sobre Interdicto de Recobrar e, infundada en el extremo de Indemnización por Daños y Perjuicios, tras considerar que la diligencia de lanzamiento ordenada en el proceso de Ejecución de Garantías número 1999-292, se realizó en el inmueble de propiedad y posesión de la demandante, el cual no fue objeto de garantía hipotecaria por parte de Roberta Pariona Vilcatoma a favor de la empresa Negusa Corp. Sociedad Anónima; y si bien, dicho lanzamiento se efectuó a mérito de un mandato judicial, sin embargo, la ahora demandante no fue emplazada o citada en el referido proceso, por lo que dicha situación de hecho se subsume en el artículo 605 del Código Procesal Civil.

\footnotetext{
${ }^{31}$ LINARES SAN ROMÁN, Juan. La valoración de la prueba. En: Revista Derecho y Cambio Social. En Línea: Recuperado en fecha 19/04/15 de: http://www.derechoycambiosocial.com/revista013/la\%20prueba.htm. Lima, 2008.
} 
Además, que por sentencia de vista, la Sala Civil de Huamanga de la Corte Superior de Justicia de Ayacucho, confirma la sentencia de primera instancia, argumentando que en la fecha en que se inició el lanzamiento la demandante se encontraba en posesión del inmueble materia de lanzamiento, siendo despojada de su posesión sin un proceso judicial previo vulnerándose su derecho al debido proceso.

Posteriormente, tenemos que producto de lo reseñado, se interponen dos recursos de casación; uno, por Sharon Frine Guzmán Miranda y el otro, por la empresa Negusa Corporación Sociedad Anónima, contra la sentencia de vista expedida por la Sala Civil de Huamanga de la Corte Superior de Justicia de Ayacucho, que confirma la sentencia apelada, que declara fundada la demanda interpuesta por Rina Paola Guzmán Pariona contra Negusa Corporación Sociedad Anónima y Sharon Frine Guzmán Miranda, sobre Interdicto de Recobrar.

En primer término, es de verse que el Recurso de Casación interpuesto por Sharon Frine Guzmán Miranda, fue declarado procedente por la causal de infracción normativa procesal, sustentada en los siguientes fundamentos: i) La sentencia de vista carece de una debida motivación, pues tanto el A quo como el Ad quem no han tomado en cuenta que el presente proceso es uno sobre Interdicto de Recobrar, cuya finalidad es defender la posesión como un derecho, y sin tomar en cuenta ello, se ha emitido una sentencia que prescinde de oficio la actuación de pruebas categóricas que acreditan fehacientemente que la demandante Rina Paola Guzmán Pariona nunca poseyó el bien inmueble materia del proceso, lo cual se encuentra acreditado con las actas levantadas en la diligencia de lanzamiento recaídas en el Expediente número 1999-292; y más bien, fue su madre Roberta Pariona Vilcatoma la posesionaria y titular del citado bien inmueble; ii) Ha obviado pronunciarse sobre situaciones que fueron puestas en conocimiento por la recurrente, como el hecho de que el Perito que realizó el dictamen pericial en el proceso fue el mismo que emitió un dictamen contradictorio a favor del Banco de Crédito del Perú al que la recurrente hipotecó el bien materia de litis y que no ha sido notificada como parte en el proceso; iii) En la Escritura Pública mediante la cual se constituye la garantía hipotecaria a favor de Negusa Corp. Sociedad Anónima no se consigna numeración alguna; ello porque en aquella fecha el bien sub materia no tenía numeración más que la consignada sin el permiso de la respectiva Municipalidad; tal es así, que existen dos viviendas con la numeración que aparece consignada en dicha propiedad; y, iv) El bien inmueble de propiedad de la suscrita tiene dos fichas y en su contenido existen serias diferencias en la identificación de las propiedades que tenían los padres de la hoy demandante; incluso ocultan sus estados civiles y todo ello para confundir la correcta administración de justicia. Siendo ello así, se puede presumir que la Escritura Pública de Anticipo de Legítima es un documento simulado, con el que se pretende desconocer la compraventa del inmueble sub litis y, por lo tanto, la titularidad de la recurrente.

En segundo lugar, se aprecia que la misma Sala Suprema declaró también procedente el recurso de casación interpuesto por la empresa demandada Negusa Corporación Sociedad Anónima, por la causal de infracción normativa procesal, sustentada en los siguientes fundamentos: i) Se ha vulnerado el principio de congruencia, porque el Colegiado Superior, al haberse pronunciado en la sentencia de vista sobre el derecho de propiedad de la demandante, se desvió del marco del debate judicial de un proceso de Interdicto de Recobrar, donde no se discute el derecho de propiedad, sino la defensa del derecho de 
posesión. El Ad quem, tras haber declarado indebidamente como propietaria a la demandante, llega a determinar que se habría producido el despojo judicial de la misma, sin antes evaluar y determinar si la actora estaba en posesión del bien sub litis, que es la premisa fundamental de la cual debió partir y que es materia de debate judicial; ii) Se ha vulnerado el principio de valoración conjunta de la prueba, porque únicamente se ha tenido en cuenta el Acta de fecha ocho de agosto de dos mil cinco; no obstante que la diligencia de lanzamiento se realizó en dos etapas, habiéndose producido la primera el día veinticinco de junio de dos mil dos, donde se acredita fehacientemente que la posesionaria del inmueble objeto de lanzamiento era Roberta Pariona Vilcatoma; sin embargo, este documento no fue valorado por el Colegiado Superior. Así también el Ad quem no ha valorado el escrito presentado por Roberta Pariona Vilcatoma, en que hace notar su calidad de posesionaria. Tampoco se ha valorado en forma conjunta y completa la Escritura de Anticipo de Legítima y la Ficha Registral número 13526, pues el proceso de Ejecución de Garantías se inició en el mes de setiembre de mil novecientos noventa y nueve, mientras que el anticipo de legítima fue otorgado con fecha nueve de marzo de dos mil uno; además fue otorgado únicamente por uno de los cónyuges, lo que demuestra que fue confeccionado como un acto jurídico simulado para inducir a error al juzgador; y, iii) Se ha vulnerado la garantía constitucional de la motivación de las sentencias judiciales, porque el Ad quem indebidamente al fundamentar el derecho de propiedad de la demandante, no ha fundamentado con suficiencia y razonabilidad los motivos que se deben evaluar para la decisión de un proceso de Interdicto de Recobrar por desalojo judicial, puesto que no han tomado en cuenta todas las pruebas relevantes como el Acta de fecha veinticinco de junio de dos mil dos donde se acredita que la posesionaria del inmueble fue Roberta Pariona Vilcatoma.

Entonces, se colige que en el presente caso, se advierte que las instancias judiciales de mérito no han resuelto debidamente las alegaciones expuestas por las partes, ni han valorado debidamente los medios probatorios, a fin de determinar si efectivamente la demandante estuvo en posesión del inmueble sub litis, pues conforme se ha señalado procede el interdicto de recobrar cuando el poseedor es despojado de su posesión, y en el caso de autos esa situación no ha quedado claramente establecida; en consecuencia, los jueces al no haber efectuado una debida motivación en sus fallos, han vulnerado el derecho al debido proceso, pues no han dado una respuesta congruente a la pretensión que se demanda.

Ergo, estando a la irregularidad procesal incurrida corresponde declarar la nulidad de las sentencias recurridas y ordenar al A quo expida nueva resolución con mejor estudio de autos y conforme a las consideraciones que anteceden.

Así, la Sala Civil Transitoria de la Corte Suprema de Justicia de la República, declaró fundados los recursos de casación interpuestos por Sharon Frine Guzmán Miranda y la empresa Negusa Corporación Sociedad Anónima, casó la sentencia impugnada, en consecuencia: nula la sentencia de vista, expedida por la Sala Civil de Huamanga de la Corte Superior de Justicia de Ayacucho; e insubsistente la sentencia, que declara fundada la demanda; y ordenó también, que el A quo emita nueva sentencia, teniendo en cuenta las referidas consideraciones. 


\section{Análisis de la resolución in comento.}

En principio, corresponde proceder a la exégesis de la procedencia de la primera casación (interpuesta por la recurrente Sharon Frine Guzmán Miranda). Así, llama la atención que en ambas instancias judiciales se haya errado al pronunciarse acerca de la propiedad del bien materia del proceso, en lugar de haberse ocupado de la naturaleza posesoria que embarga la institución jurídica, propia del interdicto de recobrar.

Entonces, se colige que no solamente se ha vulnerado el derecho a la debida motivación de las resoluciones judiciales que tienen las justiciables mencionadas, si no que, también, se ha vulnerado el principio de congruencia procesal.

Además, resulta incorrecto, por decir lo menos, que en la vía judicial no se haya advertido el conflicto de intereses en que incurrió el perito que realizó el dictamen pericial en el proceso, en razón, a que fue el mismo que emitió un dictamen contradictorio a favor del Banco de Crédito del Perú al que la recurrente hipotecó el bien materia de litis y que no ha sido notificada como parte en el proceso.

Seguidamente, concierne interpretar los extremos de la declaración de procedencia de la segunda casación (interpuesta por la empresa demandada Negusa Corporación Sociedad Anónima). Así, estimo muy preocupante, la vulneración al principio de valoración conjunta de la prueba, ello en razón que, se colige que no se tomó debidamente en cuenta el acta, por la cual se acredita indubitablemente que la posesionaria del bien sub litis, era Roberta Pariona Vilcatoma. Además, lo propio respecto del escrito presentado por esta última, donde evidencia su calidad de posesionaria.

Cabe agregar, que soy conteste con lo decidido por la Sala Civil Transitoria de la Corte Suprema de Justicia de la República, en tanto, consideramos que se pronunció de manera acertada como justa, al declarar fundados ambos recursos de casación interpuestos bajo la misma causal, esto es, por la infracción normativa procesal.

Y es que, es nuestro parecer la decisión del referido Colegiado Supremo, en resumidos términos, no solo advierte, la vulneración de derechos y principios procesales de las partes, además de disponer que el juez de primera instancia emita una nueva sentencia, observando lo evidenciado por el mismo. Si no que, a su vez, sale en defensa del sistema jurídico imperante, del Estado Constitucional de Derecho, de la Constitución, de la Ley y por supuesto, de la legitimidad, esto es, de la justicia. Lo que, dicho sea de paso, saludo sobremanera.

\section{A manera de colofón.}

Resulta sumamente lamentable como preocupante, colegir que tanto la primera (Segundo Juzgado Civil de Ayacucho), como la segunda instancia (Sala Civil de Huamanga), hayan incurrido en garrafales yerros de manera sistemática. Los mismos, que se traducen en vulneraciones de derechos de los justiciables: Sharon Frine Guzmán Miranda y la empresa Negusa Corporación Sociedad Anónima.

Esto es, que simplemente devienen en incomprensibles las vulneraciones, en el caso de la primera justiciable: i) Motivación de resoluciones judiciales. Así también, en el de la segunda justiciable: i) Principio procesal de congruencia, ii) Principio de valoración conjunta de la prueba, y iii) Motivación de resoluciones judiciales. 
En ese sentido, considero que dichos entes judiciales habrían incurrido en malicia procesal, al alterar, vía las vulneraciones referidas, el fondo del asunto sub litis. Así tenemos, que malicia procesal es: "la utilización arbitraria de los actos procesales en su conjunto (inconducta procesal genérica) o aisladamente cuando el cuerpo legal los conmina con una sanción específica (inconducta procesal específica), y el empleo de las facultades, que la ley otorga a las partes, en contraposición con los fines del proceso, obstruyendo su curso y en violación de los deberes de lealtad, probidad y buena fe" ${ }^{32}$. En iguales términos, lo propio podemos señalar del accionar de la accionante de la casación, Sharon Frine Guzmán Miranda, en vista de pretender desconocer la compraventa del bien inmueble sub Litis, esto es, su titularidad sobre el mismo.

Malicia es, por ejemplo, confabular con el notificador para que notifique en un domicilio diferente del que consta en la cédula, con el oscuro propósito que el demandado o notificado pierda sus derechos por la no comparecencia en término al proceso. En el caso de la eventual incurrencia del juez en malicia procesal, se tiene, que la misma se evidencia, verbi gratia: al correr excesivamente traslados a la partes, excesivo rigor en la formalidad al rechazar recursos o declarar nulidades recurrentemente, admitir o rechazar medios probatorios abiertamente improcedentes o procedentes respectivamente, incurrir en morosidad judicial injustificada o no sancionar (omisión cuasi cómplice) el accionar procesal abusivo de cualquiera de los sujetos señalados. ${ }^{33}$

En ese sentido, llama la atención que la Sala Civil Transitoria de la Corte Suprema de Justicia de la República, vía la resolución sub exámine (Cas. Nº 986-2012 Ayacucho), se haya limitado únicamente a casar la sentencia impugnada, anular la sentencia de vista, expedida por la Sala Civil de Huamanga de la Corte Superior de Justicia de Ayacucho; declarar insubsistente la sentencia, que declara fundada la demanda; y ordenar también, que el A quo emita nueva sentencia, teniendo en cuenta las referidas consideraciones. Ello, en tanto, el Juzgado y Sala, no fueron siquiera apercibidos por su muy cuestionable proceder procesal.

Por otro lado, aprecio el hecho que los nocivos efectos de las resoluciones judiciales impugnadas vía los recursos de casación resueltos, felizmente recientemente pueden ser paliados (y no en los tiempos acaecidos en el devenir del caso in comento). Ello, en vista de la dación de la Ley No 30199, de fecha 18/05/14, que modifica el Código Procesal Civil peruano. Dicha norma considera la posibilidad de interponer una medida cautelar, adicionando al Art. 603, del mencionado cuerpo normativo: "Procede a pedido de parte la solicitud de posesión provisoria del bien una vez que haya sido admitida la demanda, la que se sujeta a los requisitos y trámites de la medida cautelar”.

En ese orden de ideas, en opinión del Estudio Echecopar, dicha medida cautelar tendrá como finalidad que se le entregue al demandante la posesión del bien hasta que se emita sentencia firme en dicho proceso, pudiendo ser solicitada una vez admitida la demanda,

\footnotetext{
${ }^{32}$ Veni GOZAÍnI, Osvaldo A. La conducta en el proceso. Librería Editora Platense S.R.L. Buenos Aires. 1988, p. 69.

33 TORRES MANRIQUE, Jorge Isaac. Temeridad y malicia procesales al banquillo. Crónica de dos lacras jurídicas que pretenden consolidarse. En: Civil Procedure Review. En Línea: Recuperado en fecha 19/04/15 de:

http://www.civilprocedurereview.com/index.php?option=com_content\&view=article\&id=119\%3Atemeri dad-y-malicia-procesales-al-banquillo-cronica-de-dos-lacras-juridicas-que-pretendenconsolidarse\&catid=53\&Itemid=82\&lang=es. München. 2010, p. 97.
} 
para lo cual deberá reunir los requisitos y el contenido señalado en los artículos 610 y 611 del Código procesal civil. ${ }^{34}$

Finalmente, es de resaltar, que la sentencia casatoria bajo análisis, reviste especial relevancia y trascendencia, en tanto, tratándose de la equivocada ejecución de un interdicto de recobrar (además, de los derechos y principios procesales mencionados), donde el predio lanzado corresponde probadamente a un tercero, en la misma se dispone la corrección de lo correspondiente.

\section{Bibliografía}

ACOSTA OLIVO, Carlos. En: VV. AA. Diccionario procesal civil. Grupo Editorial Gaceta Jurídica. Lima, 2013.

ARAGÓN L., Luis Ángel. Diccionario jurídico de derecho procesal civil. IDEA Editores. Lima, 1995.

CABANELLAS, Guillermo. Diccionario enciclopédico de derecho usual, 23a edición. Tomo V. Buenos Aires. 1994.

CASTILLO ALVA, José Luis. LUJÁN TÚPEZ, Manuel y ZAVALETA RODRIGUEZ, Roger. Razonamiento judicial. Interpretación, argumentación y motivación de las resoluciones judiciales. Editorial Gaceta Jurídica S.A. Lima, 2004.

DEVIS ECHANDÍA, Hernando. Teoría general del proceso aplicable a toda clase de procesos. Tomo I. Editorial Universidad. Buenos Aires. 1984.

DÍAZ REVORIO, F. J. (2004). Compilador. Jurisprudencia del tribunal europeo de derechos humanos. Palestra editores. Lima.

DIEZ- PICAZO, Luis. Fundamentos del derecho civil patrimonial. Editorial Tecnos S.A. Madrid. Volúmen II, 1983.

DIEZ- PICAZO, Luis y GULLÓN, Antonio. Sistema de derecho civil. Editorial Tecnos S.A. Madrid. Tomo III, 1981.

GARCÍA BELAÚNDE, Domingo. Diccionario de jurisprudencia constitucional. Definiciones y conceptos extraídos de las resoluciones y sentencias del tribunal constitucional. Editora Jurídica Grijley, Lima, 2009.

GOZAÍNI, Oswaldo Alfredo. Elementos de derecho procesal civil. EDIAR S. A. Editora, Comercial, Industrial y Financiera. Buenos Aires, 2005.

JAMES, Philip. Introducción al derecho inglés. Editorial Temis S.A. Santa Fe de Bogotá. 1996.

LANDA ARROYO, C. (2005). Compilador. Jurisprudencia de la corte interamericana de derechos humanos. Palestra Editores. Lima.

LINARES SAN ROMÁN, Juan. La valoración de la prueba. En: Revista Derecho y Cambio Social. En Línea: Recuperado en fecha 19/04/15 de: http://www.derechoycambiosocial.com/revista013/la\%20prueba.htm. Lima, 2008.

34 S/a. Modifican interdicto de recobrar. En línea: Recuperado en fecha 19/04/15, de: http://www.elperuano.com.pe/edicion/noticia-modifican-interdicto-recobrar20409.aspx\#.VTRFOdJ_Okp. Lima. 2014. 
LORENZETTI, Ricardo Luis. Razonamiento judicial. Fundamentos de derecho privado. Editora Jurídica Grijley E.I.R.L. Lima, 2006.

MONROY CABRA, Marco Gerardo. Principios del derecho procesal civil. Editorial Temis S.A. Bogotá, 1973.

MONROY GÁLVEZ, Juan. Introducción al proceso civil. Editoriales Temis S. A. y De Belaunde \& Monroy. Santa Fe de Bogotá. 1996.

OSSORIO. Manuel. Diccionario de ciencias jurídicas, políticas y sociales. Editorial Heliasta S.R.L. Buenos Aires. 2001.

RIBÓ DURAND, Luis. Diccionario de derecho. Bosh Casa Editorial. S. A. Barcelona. 1987.

S/a. Modifican interdicto de recobrar. En línea: Recuperado en fecha 19/04/15, de: http://www.elperuano.com.pe/edicion/noticia-modifican-interdicto-recobrar20409.aspx\#.VTRFOdJ_Okp. Lima. 2014.

SAGÁSTEGUI URTEAGA, Pedro. Exégesis y sistemática del código procesal civil. Editora Jurídica Grijley, Lima, 2003.

Sentencia del Tribunal Constitucional peruano, Exp.458-2001- HC. En línea: Recuperada en fecha 18/04/15 de: http://www.tc.gob.pe/jurisprudencia/2002/00458-2001HC.html., Lima. 2002.

TICONA POSTIGO, Víctor. El derecho al debido proceso en el derecho civil. Editora Jurídica Grijley, Lima.

TORRES CARRASCO, Manuel Alberto. El nuevo recurso de casación civil. Recientes modificaciones y repaso jurisprudencial. Grupo Editorial Gaceta Jurídica. Lima, 2010.

TORRES MANRIQUE, Jorge Isaac. Temeridad y malicia procesales al banquillo. Crónica de dos lacras jurídicas que pretenden consolidarse. En: Civil Procedure Review. En Línea: Recuperado en fecha 19/04/15 de: http://www.civilprocedurereview.com/index.php?option=com_content\&view=arti cle\&id=119\%3Atemeridad-y-malicia-procesales-al-banquillo-cronica-de-doslacras-juridicas-que-pretenden-consolidarse\&catid=53\&Itemid=82\&lang=es. München. 2010.

\section{"LA REVISTA INNOVARE NO SE HACE RESPONSABLE EN NINGÚN CASO DE LOS CONTENIDOS, DATOS, CONCLUSIONES U OPINIONES VERTIDAS EN LOS ARTÍCULOS PUBLICADOS, SIENDO ESTA RESPOSABILIDAD EXCLUSIVA DEL (DE LOS) AUTOR (AUTORES)”}

